3. Geirsson A, Bavaria JE, Swarr D, Keane MG, Woo YJ, Szeto WY, et al. Fate of the residual distal and proximal aorta after acute type a dissection repair using a contemporary surgical reconstruction algorithm. Ann Thorac Surg. 2007;84:1955-64.

4. Rylski B. To replace or not to replace: that is the question. Eur J Cardiothorac Surg. 2016;50:239-40.
5. Leshnower BG, Chen EP. When and how to replace the aortic root in type A aortic dissection. Ann Cardiothorac Surg. 2016;5:377-82.

6. Norton EL, Hornsby WE, Wu X, Wolford B, Graham S, Willer CJ, et al. Aortic progression and reintervention in patients with pathogenic variants following a thoracic aortic dissection. J Thorac Cardiovasc Surg. 2021;162:1436-48.e6.
See Article page 1436.

\section{Commentary: Genetic variants in thoracic aortic disease - the root of all evil?}

\author{
Gal Levy, MD, and Abe DeAnda, Jr, MD
}

There are currently 37 known genetic variants or mutations associated with thoracic aortic disease, as was most recently summarized by Vinholo and colleagues, ${ }^{1}$ and this total may be the tip of the iceberg. Molecular genetics bolsters the ever-expanding catalogue of culprit genes that contribute to this disease and provide the potential of personalized care to individuals suffering from aortic disease. In this current study in the Journal, Yang and colleagues ${ }^{2}$ present a retrospective study comparing the operative treatment strategies for acute aortic dissection with attention to those genetic variants that may require aggressive intervention. Recognizing that genomic variants had a much greater reintervention rate after initial surgery than normal variants, they suggest aggressive root replacement and similar arch management be considered in pathogenic variant carriers at initial repair. This concept enables the idea of tailoring aortic care in a typically silent disease with lethal potential.

As noted by the authors, at the time of the initial aortic event, there is a lack of management guidelines for patients with genetic variants. This should not be surprising, as there is, for the patients in this study, a lack of recognition of patients with genetic variants at the time of presentation, since the authors selected acute type A aortic dissections as their

From the Division of Cardiovascular and Thoracic Surgery, UTMB-Galveston, Galveston, Tex.

Disclosures: Authors have nothing to disclose with regard to commercial support.

Received for publication Feb 14, 2020; accepted for publication Feb 15, 2020; available ahead of print Feb 21, 2020.

Address for reprints: Abe DeAnda, Jr, MD, Division of Cardiothoracic Surgery, UTMB-Galveston, 301 University Blvd, Galveston, TX 77551 (E-mail: abdeanda@utmb.edu).

J Thorac Cardiovasc Surg 2021;162:1450-1

$0022-5223 / \$ 36.00$

Copyright (c) 2020 by The American Association for Thoracic Surgery

https://doi.org/10.1016/j.jtcvs.2020.02.066
Check for updates

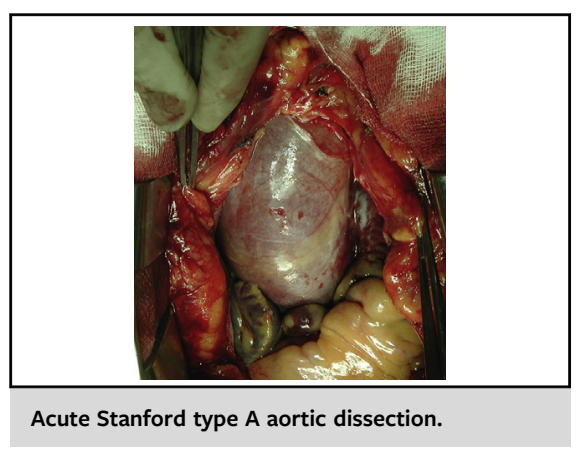

CENTRAL MESSAGE

Preoperative recognition of ge-

netic variants associated with

aortic disease may potentially

alter the surgical management of

these patients.

study cohort. If it were possible to provide the genetic information before taking the patient to the operation, the platform of genetic variant aortic disease would be transformed and the treatment algorithm would be tailored to the needs of this patient population. For patients with aneurysmal disease and/or familial thoracic aortic disease syndromes, this approach would be easier. Given the limitations of preoperative emergent genetic testing, one should hesitate to assume that more aggressive treatment should be applied universally to patients with type A dissections.

The pathogenic group in this study showed a predominance of younger, non-sex dominant, normotensive phenotypes. Beyond that, there are few identifying characters to clearly denote the pathogenic group from the benign group without knowing in advance a history of Loeys-Dietz, Ehlers-Danlos, or Marfan or a family history suggesting familial genetic mutation. The suggestion of aggressive root replacement in patients younger, without smoking history or hypertension is not without merit, considering that the data here identify this group as requiring additional procedures to address the root 
at a point in time after the initial event. It is also important to recognize that timely intervention for a type A dissection in an unstable or critical patient may require a "get-in and get-out" approach. For the highly specialized, this may be second nature to address the root during an emergent procedure. However, for the traditional cardiothoracic surgeon who is not at a specifically high-volume aortic root center, this may not even be a consideration.

Norton and colleagues ${ }^{2}$ have shed light on what may become the future of patient-specific aortic surgery. Although the technology and availability lag, the authors' vision to pursue this line of inquiry may help tame the lethalness of genetic variants in aortic disease.

\section{References}

1. Vinholo TF, Brownstein AJ, Zignashin BA, Zafar MA, Kuivaniemi H, Body SC, et al. Genes associated with thoracic aortic aneurysm and dissection: 2019 update and clinical implications. Aorta (Stamford). 2019;7:99-107.

2. Norton EL, Hornsby WE, Wu X, Wolfor B, Graham S, Willer CJ, et al. Aortic progression and reintervention in patients with pathogenic variants following a thoracic aortic dissection. J Thorac Cardiovasc Surg. 2021; 162:1436-48.e6. 